\title{
Yoga öffnet obere Atemwege
}

\author{
YOGA bei Gesundheitsproblemen - Die bewusste Atmung ist ein ständiger \\ Begleiter aller Yogahaltungen. Die Atmung erleichtert das Hineingehen in eine Haltung. \\ Komplementär dazu schafft diese Haltung eine Erweiterung des Atemraums. Das wird \\ am Beispiel der Fischposition deutlich.
}

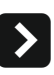

Das körperliche und mentale Wohlgefühl durch die Atmung zu fördern, ist ein zentrales Ziel des Yoga. Atemtechniken sind darum wesentliche Anteile der Yogapraxis. Diese Übungen werden unter dem Begriff „Pranayama“ vereint. Wer sich ganz auf seine Atmung und Bewegung konzentrieren kann, verbessert seine Selbstwahrnehmung und schöpft Kraft. Ganz konzentriert zu sein, vermittelt ein gutes Gefühl - beim Yoga, aber auch im Alltag. Die Fischposition bringt Ihren Körper in eine eher ungewohnte Haltung und dehnt die Brust- und Halswirbelsäule stark gegen die gewohnte Richtung. Sie sollten darum beim Üben sehr vorsichtig vorgehen.

\section{Schnelle Wirkung}

Die Siegeratmung: Stellen Sie sich aufrecht hin, verschränken Sie Ihre Finger und legen Sie Ihre Hände auf dem Bauch ab. Atmen Sie durch die Nase ein und strecken Sie Ihre Arme über dem Kopf aus. Die Handinnenflächen zeigen zur Decke. Strecken Sie sich ganz lang. Atmen Sie durch den Mund(!) aus, als ob Sie einen Spiegel oder ein Brillenglas anhauchen wollen und senken Sie dabei Ihre Arme bis sie wieder auf dem Bauch liegen. Wiederholen Sie diese Übung mindestens sechsmal.

\section{Anhaltende Wirkung}

Der Fisch: Die Ausgangsposition für die Fischposition ist der Sitz auf dem Boden. Die Beine sind geschlossen und bis in die Zehen hinein gestreckt. Die Hände sind dicht neben dem Becken aufgestellt und unterstützen die aufrechte Sitzhaltung. Die Finger zeigen in Richtung des Körpers. Aus dieser Position heraus während einer Ausatmung die Arme beugen und den Oberkörper langsam absenken. Die Bewegung beenden, wenn der Oberkörper leicht und bequem auf den Unterarmen ruht. Vergewissern Sie sich, dass Ihre Ellenbogengelenke genau unter Ihren Schultergelenken abgelegt sind. Diese vertikale Ausrichtung schützt die Gelenke (Foto 1).

Mit einer Einatmung beugen Sie Ihre Brustwirbelsäule rückwärts. Ihren Kopf und Hals beziehen Sie in diese Rückwärtsbeugung mit ein. Die Beugung so weit ausführen bis die Kopfkrone auf

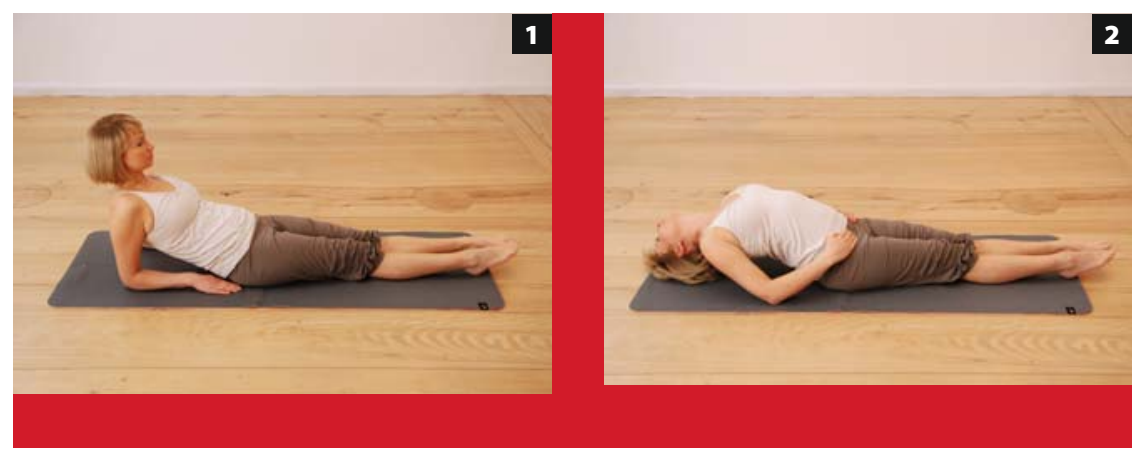

dem Boden ruht. Ihre Hände ruhen in den Leisten. Der Brustkorb ist angehoben, das Becken bleibt auf dem Boden. Halten Sie diese Position während Sie sechsmal komplett durch die Nase ein- und ausatmen (Foto 2).

Zur Auflösung der Haltung bewegen Sie Ihre Arme mit einer Ausatmung seitwärts bis der Oberkörper wieder vollständig auf dem Boden ruht. Legen Sie Ihre Arme neben Ihrem Körper ab. Spüren Sie Ihren Körper auf dem Boden und nehmen Sie ganz bewusst den Raum zwischen den Schulterblättern wahr. Wer möchte, kann dabei die Augen schließen.

Prof. Dr. Ingrid Kollak

- Alice-Salomon Fachhochschule Berlin Yoga-Lehrerin BDY/EYU

_ Email: kollak@asfh-berlin.de (Betreff: Yoga bei ...)

\section{BUCH-TIPP!}

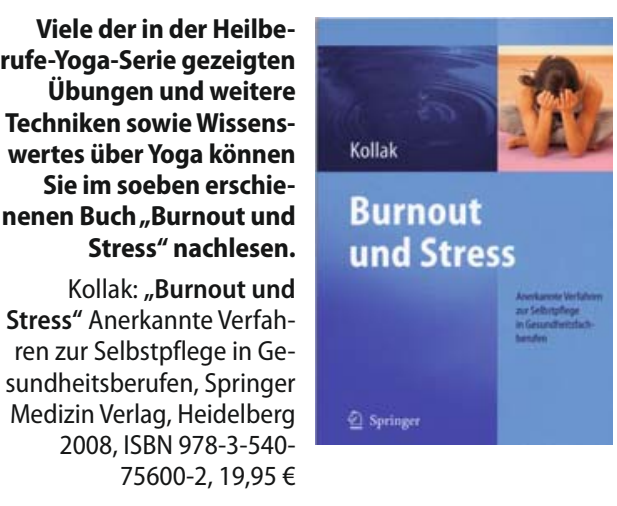

